\title{
ERRATUM II
}

Erratum to: Morphological and Microstructural Evidences of Paleo-Seismic Occurrences in an Earthquake Prone Zone of Tripura, India

\section{Sudip Dey*, Sushmita Paul, Prasamita Sarkar}

Department of Geography and Disaster Management Tripura University, Suryamaninagar 799130, Tripura (West), India

(C) China University of Geosciences and Springer-Verlag Berlin Heidelberg 2014

Erratum to: Journal of Earth Science

DOI: $10.1007 / \mathbf{s} 12583-014-0430-x$

The original version of this article unfortunately contained a mistake. The presentation of the title was incorrect. The corrected title is given below.

Morphological and Microstructural Evidences of Paleo-Seismic Occurrences in an Earthquake Prone Zone of Tripura, India

The online version of the original article can be found at http://link.springer.com/article/10.1007/s12583-014-0430-x

*Corresponding author: sudip_geo@rediffmail.com 